\title{
Risk Transfer and the Insurance Industry
}

\author{
Gerd Häusler ${ }^{1}$ \\ International Capital Markets Department, International Monetary Fund, Washington, DC, USA. \\ E-mail: ghaeusler@imf.org
}

This paper asks whether the transfer of risk from banking to non-banking institutions, such as insurers, has reduced risk for the financial system as a whole or merely shifted it to less transparent sectors. If the latter is the case, then it may be that new forms of risk and vulnerability are being introduced into the global financial system.

The Geneva Papers (2005) 30, 121-127. doi:10.1057/palgrave.gpp.2510004

Keywords: credit risk transfer; insurance industry; financial stability

\section{Introduction}

Twenty years ago, banks and insurance companies maximized the size of their balance sheets: banks accumulated assets in search of a larger market share, and the insurance industry was mostly liability driven. Asset gathering seemed to entail little or no cost of capital. The terms financial system and banking system were largely synonymous. Much has changed since then.

In recent years, risk has increasingly transferred from banks to nonbank institutions such as mutual funds, pension funds, insurers, and hedge funds. Banks generally try to distribute the risk that originates with them - particularly concentrations of credit risk - in order to optimize the use of their balance sheets and as an integral part of their risk management practice. ${ }^{2}$ Some nonbank institutions, in certain markets, have demonstrated a strong or growing appetite for credit risk exposure in various forms. These include insurers who increasingly view credit instruments as a relatively stable investment to meet their liabilities. The development of new credit instruments, particularly derivatives, has facilitated this process.

The transfer of risk to nonbanking sectors has raised concerns about "where the risk has gone"; whether risk has been widely dispersed or concentrated; and whether the recipients of risk are able to manage it. Most observers agree that the transfer of credit has improved the banking sector's ability to manage risk, and hence the stability of the banking system. A wide variety of nonbank institutions have taken on that risk. However, the relatively less transparent nature of some nonbanking institutions, their different systems of regulation, and, in some cases, less developed risk management skills have raised questions about whether a reallocation of credit risk has reduced risk for the financial system as a whole or merely shifted it to less transparent sectors. If the

${ }^{1}$ The views expressed are those of the author, and do not necessarily represent the views of the IMF or IMF policy.

${ }^{2}$ International Association of Insurance Supervisors (2003); Financial Services Authority (2002); Rule (2001). 
latter is the case, it may be that new forms of risk and vulnerability are being introduced into the global financial system.

This paper discusses the impact on the financial stability of insurers' investment behaviour and risk management in the large mature markets. Although policy implications differ from one market to the other, useful general lessons may be drawn for all markets and, in particular, for emerging market economies with developing capital markets.

\section{Credit risk transfer and insurers' investment decisions}

The recent growth in credit derivatives as complex credit risk transfer instruments, and the lack of transparency on such transactions, have prompted concerns about where risk has migrated from the banking sector. ${ }^{3}$ Various official bodies and private sector organizations have undertaken work, including surveys of market participants, to shed more light on this issue. In gross terms, banks have conducted credit derivative transactions, largely with other banks, to achieve their desired exposures. The insurance sector is a net taker of credit risk (through these derivatives), but these net positions form a small part (generally 3 to 4 per cent) of their asset portfolios. Moreover, exposure to traditional credit instruments, broadly defined, has been part of insurers' investment portfolios for a long time, and substantial in volume. In recent years, there seems to have been relatively stronger growth in the credit exposure of the insurance sector compared to the banking sector.

The patterns and levels of involvement of insurers in credit instruments have differed widely by countries and regions. The structure of national financial systems and capital markets, and insurance regulation are instrumental factors in explaining the observed differences in insurers' investment activities. Also increasingly important are accounting standards and rating agencies in certain regions.

The capital market structure in the United States has facilitated corporate bond investments for insurers, while the systems in continental Europe, the United Kingdom, and Japan have led insurers to rely more on government securities, equities, and loans, respectively. As corporate bond and credit markets continue to develop outside the United States, the broad shift in credit exposure from banks to insurers is expected to continue. Similarly, today we see relatively more credit specialists and market-oriented risk management systems among U.S. insurers; however, the trend in other markets is clear, and larger European insurers are deepening their credit risk management skills.

The risk-based capital regimes in the United States and Japan encourage holdings of investment-grade credit and discourage relatively large equity holdings, while European solvency regulations focus largely on premium volumes and little on asset composition in setting minimum capital standards. Risk-based solvency standards also seem to stimulate greater development of risk management systems relative to regulatory regimes that rely on premium volumes or apply strict limits on the investment portfolios of insurers.

\footnotetext{
${ }^{3}$ IMF (2002).
} 
Importantly, there is less transfer of "real" - as opposed to notional - credit risk, particularly via credit derivatives, outside the banking sector and to the insurance industry than is generally perceived. Much of the credit risk transfer activity has been among banks. This is generally a positive development, because banks increasingly focus on reducing risk concentration and aim to diversify geographic and sectoral risks. One way of describing this development is as a modern form of syndication.

There are some concerns about the participation of small- and medium-sized institutions (banks and insurers) where (a) market scrutiny and related transparency is more limited, (b) risk management capabilities are generally less developed, and (c) the inclination to reach for higher returns may be greater at certain points in the economic cycle (e.g. when credit spreads are tight or the demand for local loans is weak).

\section{Implications for financial stability}

Our study draws some conclusions on the impact on financial stability of life insurers' investment behaviour and risk management activities in the United States, the United Kingdom, continental Europe, and Japan. ${ }^{4}$

Greater portfolio allocation to credit instruments by insurers is, or would be, a positive market development but only if risk management and regulatory oversight are improved as well. Credit products can provide a more predictable return for many life insurers, and would strengthen financial stability more generally. This is because corporate bonds tend to be a better match for insurers' liabilities and are a less volatile investment than equities, providing an attractive risk-adjusted return.

The risk management programmes that are being developed by many large insurers are encouraging and, as the reallocation to credit proceeds, it needs to be accompanied by a continued upgrading of the risk management process. The reallocation of credit risk to insurers that has taken place and improvements to their risk management capabilities, combined with the recovery in equity markets, have reduced vulnerabilities and enhanced financial stability.

National and regional market structures, and their evolution, are among the most significant influences on portfolio allocations, approaches to risk management, and the broader transfer of credit risk. Regulators should anticipate a growing appetite for credit, and should seek to support and facilitate the further development of credit markets. With highly developed and extensive credit markets in the United States, U.S. life insurers hold more of their assets in credit than in any other asset class. At the same time, as credit markets deepen in the Euro area, European insurers are expected to increase their credit exposures, including the use of synthetic portfolio products, tailored to their particular asset-liability management needs.

In Europe, therefore, policymakers are encouraged to support the continued strong growth of the corporate bond market, as well as developments across the European Union (EU) to facilitate mortgage-backed and other asset-backed securities. Likewise, the True Sale Initiative in Germany is welcome as a means for supporting small- and

\footnotetext{
${ }^{4}$ IMF (2004).
} 
medium-sized business lending and for providing a cash credit instrument that insurers should find attractive. Although only a by-product of the initiative, this is a positive development.

In the area of credit derivatives, policymakers should continue to encourage increased transparency and standardization through market initiatives, especially by the International Swaps and Derivatives Association. This should facilitate a broader market participation and a deeper, more liquid market. There is also much room to improve regulatory reporting of credit risk (including the disaggregation of credit and risk exposures in order to act as an early warning indicator). As the derivatives activity of financial institutions become larger and more complex, disaggregating market exposures become increasingly important, especially in the corporate bond market.

Regulatory and supervisory standards have been significant influences on the reallocation of risk and the development of risk management systems. We encourage supervisors to implement risk-based solvency standards, which align prudential requirements more closely with insurance companies' overall risks, and encourage ongoing improvements in risk management.

- We are encouraged by the relatively more market and risk-sensitive solvency regimes proposed under Solvency II in the EU and CP 195 in the United Kingdom. We would encourage Japanese insurance regulators to use the opportunity of the current financial market recovery to introduce stricter and more market-oriented standards to their existing, and sound, risk-based capital regime.

- A prerequisite to any increase in credit exposure by insurers should be a thorough review and upgrading of risk management systems. Among the larger, internationally active insurers, an increased focus on risk management is generally under way. In the last few years, this has included greater use of more sophisticated models and experienced credit professionals; there may be doubts, however, about the ability of smaller insurers to keep up with increasingly demanding risk management requirements.

- Consistent with this approach, we would encourage policymakers to consider removing prescriptive regulations related to investment strategies and product pricing - including effective minimum-guaranteed returns on life insurance liabilities.

- Supervisory resources should be enhanced, with further investments in people, systems, and training, so as to better enable supervisors to evaluate and monitor the risk management models that will increasingly be required of insurers.

- Policymakers should also enhance the dialogue among mature market supervisors, and promote the increasing discussions among insurance risk managers in Europe and elsewhere. We welcome efforts by the IAIS, the Financial Stability Forum, and the Joint Forum in this area.

Rating agencies are a significant influence on reinsurance companies and monoline credit insurers but should not be relied upon as a substitute for appropriate supervision. The influence of rating agencies in these insurance sectors reflects the essentially institutional markets in which they operate. To reduce the disproportionate reliance on rating agencies, greater transparency, and, in some jurisdictions, greater supervision of the business activities of reinsurers would seem appropriate. 
Policymakers and standard setters recognize the importance of ensuring that the financial and regulatory accounts provide an accurate reflection of an insurance company's financial position. The current financial accounting debate strives to improve the disclosure of balance sheet risks within the insurance sector, while providing an accurate and fair reflection of the "business reality" of insurance activities.

- This is a difficult balance, as the optionality embedded in many life insurance products has not been fully reflected in insurers' reports to date, and many insurers seek to manage these risks over longer periods.

- We recognize the concern among some authorities and insurers that fair-value accounting proposals may cause increased volatility in reported earnings. ${ }^{5}$

- We would encourage standard setters to consider employing fair value or market value principles as part of enhanced financial disclosures, for example, as supplemental disclosures and measures, and possibly sensitivities, which should improve reporting standards and broaden market understanding of insurance risks.

- Fair value accounting is likely to accelerate the tendency of the insurance industry to "push out" financial risks to other sectors of the economy (see below).

\section{Looking forward}

Policymakers should be aware that improvements in risk management and reporting, while desirable, may have unforeseen market implications. Specifically, the long-term nature of the insurance business will likely come under increased scrutiny and pressure in view of some of the market-based measures that policymakers and standard setters are pursuing or considering. It is possible that the ability of the insurance industry to act as a shock absorber for the financial system could be reduced, and, in the process, the average duration of a life insurance policy decreased.

It is likely that many insurers will take steps to reduce the risk profile of both insurance products and investment portfolios, that is, "de-risk" their balance sheets. In the process, risk is likely to continue to be passed to other less sophisticated participants and/or end-users, namely households, whether in their life insurance policies, mortgages, mutual funds, or pensions.

As more risks are reallocated through the capital markets and across previously distinct sectors, the household sector may increasingly bear more of the risks previously borne by financial institutions such as insurance companies and pension funds. For example, the introduction of fair-value accounting could reveal any mispricing of embedded options in insurance contracts. The potential loss of competitiveness and impact on shareholders from increasing premium charges would prompt insurance companies to drop these options, thereby forcing policy holders to manage the additional risk themselves. Another possibility is that insurance companies may not have sufficient incentive to supply the annuity products necessary to hedge

\footnotetext{
${ }^{5}$ Häusler (2004).
} 
126

the pension liability or longevity risks facing pension funds and the household sector more generally.

As risk transfer to the household sector becomes more widespread, the official sector may perceive that individuals are ill-equipped to manage the additional risk. The increased vulnerability of this politically important group could compel governments to "do something" to "protect" households. Potential government actions could include (a) propping up asset prices in cases in which markets are perceived as "too big to fall", (b) changing the rules of the game, such as introducing more consumer protection or supervisory forbearance, or (c) assuming some of the risk transferred to households with subsidies or tax holidays. Alternatively, or in addition to the above, governments could take unanticipated actions with the intent to protect consumers.

The difficulty with such government actions is that they can prevent the proper pricing and allocation of risk. For example, insurance companies would not be inclined to face the potential loss of competitiveness by properly pricing the embedded options in insurance policies, especially if they perceived that the government would bail out policy holders if needed. Such government support also introduces a new form of moral hazard that induces increased risk taking by the private sector by mis-pricing risk. In the above example, government policies would crowd out private initiatives to address mis-pricing of financial assets because of the expected government support that would be forthcoming if households faced collective financial ruin. Perhaps this also implies heightened demands for supervisory forbearance during times of market volatility or crises.

In a nutshell, when retirement income, be it life insurance policies, pensions, or mutual funds, is subject to the volatility of the markets - which in turn depends on the movements of the business cycle - the question is who bears the market risk. The more the financial intermediaries mentioned above are subject to fair-value accounting and mark to market reflecting cyclical movements - the higher is the incentive for them to pass on some of the financial risk to the households, which often lack a full understanding of the risks they incur. Such a development could ultimately backfire on those who sold the financial products. Depending on the business culture, such politically sensitive developments could ultimately lead either to new regulation, as noted above (e.g. in Europe) or new litigation (e.g. in the United States).

Fortunately, there are ways to encourage more market-based solutions in this scenario, although it would require upgrading the design of capital market policies across the board. First, the "rules of the game" for financial market participants would need to be fixed ex ante so as to ensure certainty and finality to financial contracts and transactions. Secondly, government and supervisory actions would need to be predictable. Thirdly, the financial industry would have to both be and be perceived as proactive. Financial market participants would need to take on the political job of explaining the changing role and what it means for customers such as households, particularly if they are hedging away their risks. Lastly, insurers should not lose sight of the fact that their fundamental business is taking on risk. As they improve hedging of existing financial risks - and households take on part of that risk - insurers may need to think about new products for households to avoid undue vulnerabilities. 
An even greater challenge emanating from the increased risk transfer to the household sector is bringing retail consumers up to speed along the steep learning curve for managing risk. It is necessary that households become aware of the risk they are increasingly bearing, and their skills can develop through better communication and education. The process that would bridge the gap between the households' increased assumption of risk and their understanding of that risk will likely take decades if not generations.

The financial industry, together with educational and social institutions, must rise to the challenge of accelerating the learning process and developing new financial instruments and practices that can enable households to assess and manage their new financial risks. Without innovative private-sector solutions, the only alternative may be the inferior solutions of the public sector noted above.

\section{References}

Financial Services Authority (2002) Cross-sector risk transfers discussion paper, May.

Häusler, G. (2004) 'The insurance industry, systemic financial stability, and fair value accounting', The Geneva Papers on Risk and Insurance 29(1): 63-70.

International Association of Insurance Supervisors (IAIS) (2003) Credit risk transfer between insurance, banking and other financial sectors (March) Basel.

IMF (2002) Global financial stability report (March), World Economic and Financial Surveys, Washington. IMF (2004) 'Risk transfer and the insurance industry', Global financial stability report (March), World Economic and Financial Surveys, Washington.

Rule, D. (2001) 'Risk transfer between banks, insurance companies and capital markets: an overview', in Financial Stability Review, London: Bank of England, (December): 137-159.

\section{About the Author}

Gerd Häusler is the Counsellor and Director, International Capital Markets, International Monetary Fund. Previously, he was a Senior Advisor on strategic issues to Deutsche Börse AG in Frankfurt. He has a range of public and private sector experience, including serving as a member of the Directorate and member of the Central Bank Council of the Deutsche Bundesbank. He also held various positions with the Bundesbank, which included an active responsibility for work on international capital markets issues and reforms. He also served at the Bank for International Settlements. At Dresdner Bank AG, Häusler oversaw its global markets activities. He served as chair of Dresdner Kleinwort Benson in London from December 1997 until his resignation from the Dresdner Group in May 2000. Häusler studied law and economics and holds a law degree from the University of Frankfurt. 